from playing a major role in preparing a defence of the law, and that the state had therefore prejudiced its own chances of defeating the law suit.

Both, however, are now preparing for the legal battles that lie ahead. And even if ACLU wins in Little Rock - as seems likely, given the liberal background of Judge William Overton and the way he has handled the case so far - next time round the arguments could be tougher to defeat.

One passage in the Arkansas bill, for example, speaks of creation science being based on the explanation that the world was created ex nihilo, a passage which theology professor Langdon Gilkey of the University of Chicago described as "the most religious" of various statements implying the involvement of a God, since "there are no other sources at work". The new version of the model bill, however, which is being circulated by $\mathrm{Mr}$ Paul Ellwanger of Citizens for Fairness in Education of South Carolina, merely states that creation science must be based on "evidences that indicate creation of the Universe, matter and energy suddenly"'.

Given the fact that challenges from creationists are unlikely to evaporate, even if they lose the Arkansas case, ACLU is asking the judge for a "finding of fact" that any science must be based on natural laws and must be explanatory, falsifiable and tentative, criteria which they hope will rule out creation science as a genuine science, however it is described.

David Dickson

\section{UK cancer research}

\section{Unequal shares}

If the Medical Research Council's (MRC) reshuffle in the allocation of funds for cancer research in Britain was intended as a bid to save money, it has been largely unsuccessful. The complete withdrawal of financial support from two cancer research institutes in Manchester and Glasgow has saved the council a paltry $£ 0.5$ million.

Instead, it seems, the changes - announced last month in the council's annual report - were aimed at a rationalization of administration in the Patterson and Beatson cancer research institutes in Manchester and Glasgow. Since 1970 the two independent laboratories have been financed by a joint committee of the Cancer Research Campaign (CRC) and the MRC, with the two bodies taking equal financial responsibility. "The MRC's decision to relinquish financial commitment to the CRC," says Dr John Paul, director of the Beatson laboratories, "has made administration here much easier. Working for two paymasters can become complicated."

The Beatson and Patterson laboratories may benefit from dependence on the publicly-supported CRC, but the Institute of Cancer Research in London (ICR) is left as pig-in-the-middlc. It had been hoped

\title{
Painful adaptation at cancer institute
}

The problems of the British Institute of Cancer Research (ICR) stem largely from the events of four years ago, when its funds were substantially cut and put on a basis unusual for a British institute. The block grant to ICR has been tapering away for the past few years. From next April, research groups will have to compete exclusively for funds with other applicants to the Medical Research Council and the Cancer Research Campaign. To make matters more complicated, block funding of laboratory services has now also been withdrawn so that, for example, a research group which needs electron microscopy is now expected to obtain sufficient funds to pay for it as a properly costed service; consequently ICR will be able to maintain an electron microscopy facility only if there is sufficient demand and cash from the research units to support it continually.

Worse still, in the period between the sudden early retirement of the previous director of ICR, Dr Thomas Symington, in August 1977 and the appointment last year of Dr Robin Weiss, little had been done to adjust to the new circumstances. Indeed, ICR had gone on spending almost as though its total funds had not been cut by about 18 per cent, with the result that Dr Weiss inherited a deficit of about $£ 1$ million even though the Imperial Cancer Research Fund had donated about the same amount to help stave off the day of reckoning.

Since his arrival, Dr Weiss has had to clear the $£ 1$ million deficit and adjust to an annual budget that is now about $£ 6.5$ million $-£ 4$ million from the Medical Research Council and the Cancer Research Campaign, the rest from legacies, the National Health Service, endowments and granting bodies. About $£ 400,000$ a year has been saved by early retirements, the freezing of

that the MRC could allocate further funds to the ICR because of its divorce from the other two laboratories. But in practice the council has stepped up its commitment to the ICR by just 10 per cent, leaving the funding shared $60: 40$ with the CRC. This year the council also gave the institute $£ 0.5$ million for equipment, but this cannot be guaranteed in the future, says the MRC.

Dr Robin Weiss, ICR director, maintains that the reshuffle has had no immediate effect on the institute. But he is concerned about the future: "With the present arrangement of joint funding, I sometimes worry that we become neither's ultimate responsibility.",

In this financial crisis, it would seem logical to predict that the CRC would be loyal to its wholly CRC-funded bodies and that the MRC's responsibility would rest preferentially with its own units. That vacancies and other means - for example, ICR no longer has laboratory cleaners. (Has anybody noticed?) About 45 members of staff have gone, a loss offset because Dr Weiss, with separate funds linked with his appointment, has brought in about 20 new people to establish a core of molecular and cellular geneticists.

But now, Dr Weiss and his newly appointed deputy director, Dr Tony Davies, have to find more savings. Unless some means can be found to spread the contraction over four years or so, by which time more natural or voluntary retirements will have done the trick, it looks as if there will have to be perhaps 50 compulsory redundances.

One immediate threat is to the Division of Tumour Immunology under Professor Peter Alexander at the Sutton branch of ICR. As a result of recent site visits, the Medical Research Council and the Cancer Research Campaign have very substantially cut the funds of this division, leaving uncertain the future of all the tenured staff.

Dr Weiss is not convinced of the justification of this drastic cut when he sees little or no evidence that either the council or the campaign is cutting back on tumour immunology in their own units. By similar reasoning, he also fears for the future of radiobiological research at ICR. With the Medical Research Council about to continue its large Radiobiology Unit under a new director, and with the Cancer Research Campaign committed to its Gray Laboratory in Northwood, Dr Weiss wonders if they will see fit to continue support for radiobiology at ICR, in spite of its good record and close links with clinical radiotherapeutics. Dr Weiss holds that the institute is better placed to integrate radiobiology with other research activities than other establishments.

Peter Newmark

leaves the ICR in a rather vulnerable position. For there is no agreement, says Dr Weiss, that the financially healthier CRC should make good where the MRC falters.

Perhaps, though, the concern of the ICR for its future stems from its rough ride through the cuts of 1977. And the MRC is not last to admit that the financial status of the institute is far weaker than that of the Beatson or Patterson laboratories.

And while the CRC and MRC swear allegiance, one message emerges loud and clear, affirming Dr Weiss' concern. The CRC, dependent as it is on finance from the public, can in no way guarantee to act as back-up to the MRC with its government funding under continual threat. It is understandable that the ICR, funded by both bodies, should look nervously towards future government cutbacks.

Susan Douglas 